some of the AI jargon and relate the new ideas to established topics such as databases and query languages. The references show the same careful mix; they are comprehensive but up to date throughout.

The most obvious manifestation of the book's maturity, apart from style and balance, is that Sowa manages to convince the reader that most of his diverse material can be brought together under a single theoretical idea, the "conceptual graph". This is a formal, symbolic structure which can be manipulated by a computer, and which can represent many types of human knowledge. By the end of the book one is convinced that the concept may be sufficient to support machine-reasoning, language (syntax and semantics), decisionmaking, learning and (just possibly) creativity. Those familiar with AI will find many familiar themes, but the integration of subjects and the extensive investigation of the formal properties of symbolic structures is impressive.

I am less sure about Sowa's discussions of the human equivalents of these machine processes. Certainly his knowledge of and respect for the work of psychologists is refreshing. There is even a hint of affection for people, which I often miss in the machine-obsessed books of the AI world, however good they may be technically. But while the psychological material broadens and enriches the book, to say that the fields are "unified" is a little strong. More significantly, however, is that the attempt at "unification" is really an attempt on the terms of AI, not those of cognitive psychology. The links which are made between the performance of programs and observations made by psychologists can be somewhat superficial and unconvincing. They appear to be included to show us that programs can show interesting features of intelligence, not that they have truly human characteristics of intelligence. There is little effort to consider whether the key concept of the conceptual graph can explain in any detail the things that the human mind does not do, as well as things it can do. One suspects that - like other AI ideas - the conceptual graph is powerful enough to encompass many bad theories of mind as well as good ones.

Conceptual Structures is not the missing classic, the book that really achieves a unification of the two fields, but it is one of the best attempts that I have seen. Perhaps the AI traditions of imagination and vigorous inventiveness are still too far from the scientific tradition of systematic experimentation respected by cognitive psychologists. The book is nevertheless instructive and entertaining, detailed but economical. It would be on my list of six AI books to take to a desert island, and any student of cognitive science will find it very rewarding.

John Fox is Head of the Biomedical Computing Unit at the Imperial Cancer Research Fund Laboratories, London.

\section{Unhealthy business}

\section{Robert Ubell}

The Medical Industrial Complex.

By Stanley Wohl.

Harmony Books, New York: 1984.

Pp.218. \$14.95.

IN his farewell address to the nation, President Dwight D. Eisenhower warned of the ominous encroachment of the "military-industrial complex" into American life. In 1980, Dr Arnold Relman, editor of The New England Journal of Medicine, raised another spectre, the threat of the "medical-industrial complex". Relman had noticed that profitmaking groups had suddenly assumed ownership of a great network of hospitals, ambulatory'surgical centres, free-standing emergency rooms, diagnostic laboratories, alcoholic treatment facilities and a range of other health-care services.

In little more than a generation, corporations have leaped from owning a handful to controlling about a third of the country's community hospitals, mostly in affluent suburbs. Today, for-profit systems own nearly 400,000 hospital beds as part of a $\$ 118$ billion industry, which includes the vast clinical supply business pharmaceuticals, medical technology, food services and so on. One dollar in three spent on health care in the United States goes to corporations. Relman rightly feared that the result would be a return to "two-tier" care for Americans - one for those who can pay and another, far less adequate and less accessible, for the poor.

Adopting Relman's apt phrase as the title for his book, Stanley Wohl, a physician on the staff of the Stanford Medical Center and president of his own medical research and service company, offers us an exposé of the medical system. The dust jacket tells us that Wohl's book "picks up" from Paul Starr's PulitzerPrize-winning work, The Social Transformation of American Medicine (for review see Nature 304, 667; 1983). But Wohl provides neither Starr's historical perspective and keen analytical skill, nor does he go beyond Relman's original observations.

Wohl re-states what others have already concluded: the introduction of the corporation as a provider of health-care is likely to exacerbate, rather than relieve, the more intractable features of the system. To boost profits, corporations will further inflate the price of health care, despite claims that for-profit networks are best at containing costs through rational organization, economies of scale and tougher management. Recent studies, comparing "investor-owned", with non-profit hospitals, reveal that, on average, private chains charge more. Wohl quotes the head of American Federation of Hospitals, the business association of the private chains, as saying, "You can't be both newer and cheaper and we never said we're cheaper'.

American medicine is already the most wasteful in the world, annually spending $\$ 1,500$ per capita on health care - much more than any other nation. Despite Wohl's claim that the United States delivers "the highest quality [care] on earth", a new survey carried out by The Economist shows otherwise. In neither life expectancy nor infant-mortality rates the two key indicators of national health does the United States score best. A number of other industrialized countries are out in front. For instance life expectancy in Japan is 77 years $(75$ years in the United States) and infant mortality 7 per 1,000 live births (12 in the United States). And while (for example) Britain spends almost three-quarters less than the United States on health - about $\$ 400$ per capita - Britain is only a year behind the United States in life expectancy and equal in infant-mortality rate.

Wohl hopes that the American system can be saved by preserving the autonomy and authority of the physicians themselves. When doctors are in control, Wohl believes, the national interest will be served. But, by and large, American doctors have not performed well at keeping costs down, nor do patients fare best when physicians retain complete control. American doctors have fought a centurylong battle to keep medicine as a profitable product rather than a public trust, ultimately setting the stage for the corporate invasion. Now, ironically, doctors are being forced to become company men, working for wages. Turning once again to the doctors for help does not appear to be wise.

In his comedy-thriller The Man Who Knew Too Much, Alfred Hitchcock guessed that the "commodification" of health care was one of the nastier secrets in American medicine. In that movie, Jimmy Stewart plays a mid-western doctor on holiday in North Africa. Doris Day plays his wife.

DORIS DAY: Do you know what's paying for this trip?

JIMMY STEWART: What?

DORIS DAY: Mrs Campbell's gallstones. And the pearls you bought me in Paris? Paid for by Johnny Smith's tonsils.

JIMMY STEWART: You know, I never thought of it that way.

DORIS DAY: What would they think of us, if they heard us back home?

The folks back home, then as now, uncritically accept the principle that medicine is a commodity, to be bought and sold on the market, with profits going to controlling interests. That is why Wohl's proposals for reform - which include the corporate chains as a key ingredient in medical delivery - act much like a thin hospital sheet. As he pulls it up to cover his head, his toes stick out in the cold.

Robert Ubell is a scientific and medical publisher and editor in New York. 